\title{
PERSEPSI BODY IMAGE DENGAN KEBIASAAN JAJAN MAHASISWA UNIVERSITAS NEGERI SURABAYA (KAMPUS KETINTANG)
}

\author{
Nila Anggita Nur Faizah, Amalia Ruhana \\ (Universitas Negeri Surabaya)
}

\begin{abstract}
Body image is the subjective imagination of a person regarding the judgments of other on his body. The ideal body image can encourage someone to do things such as physical changes and other changes, namely snack consumption patterns. This is often experienced by students. This study aims to determine the relationship between perceptions of body image and snacking habits in students. The research targets were Universitas Negeri Surabaya students who were on the Ketintang campus with a sample of 100 people who had met the inclusion criteria. This study used an observational analytical study design with a crosssectional approach. The instruments used in this study are Body Shape Questionnaire and interviews using a semi-quantitative Food Frequency Questionnaire. The result is $56 \%$ of respondents' body image perceptions negative and 70\% of respondents admit to snacking frequently. The resuts of the correlation test showed that there was no relationship between perception of body image and the respondent's eating habits $(p>0,05)$. It can be concluded that most respondents are not satisfied with their body image, even though the majority of them often consume snacks every day. It is suggested that students need to get good nutrition education and learning related to body image perception in order to have a positive body image perception. Further research is needed to determine other factors that can affect the perception of body image in students.
\end{abstract}

Keywords: Body image; snack habits; college student.

\begin{abstract}
Abstrak
Body image merupakan imajinasi subyektif dari seseorang mengenai penilaian orang lain terhadap tubuhnya. Body image ideal dapat mendorong seseorang untuk melakukan halhal seperti perubahan fisik dan perubahan lain yaitu pola konsumsi jajan. Hal ini seringkali dialami oleh mahasiswa. Penelitian ini bertujuan untuk mengetahui hubungan antara persepsi body image dengan kebiasaan jajan pada mahasiswa. Sasaran penelitian merupakan Mahasiswa Universitas Negeri Surabaya yang berada di kampus Ketintang dengan jumlah sampel 100 orang yang sudah memenuhi kriteria inklusi. Penelitian ini menggunakan desain penelitian analitik observasional dengan pendekatan cross-sectional. Instrumen yang digunakan dalam penelitian yaitu kuesioner Body Shape Questionnaire dan wawancara menggunakan form semi kuantitatif Food Frequency Questionnaire. Hasilnya $56 \%$ responden memiliki persepsi body image negatif dan $70 \%$ responden mengaku sering jajan. Hasil uji korelasi menunjukkan tidak adanya hubungan antara persepsi body image dengan kebiasaan jajan responden ( $p>0,05)$. Dapat disimpulkan bahwa sebagian besar responden kurang puas dengan citra tubuhnya, meskipun begitu tetap saja mayoritas dari mereka sering mengonsumsi jajan setiap harinya. Disarankan mahasiswa perlu mendapatkan edukasi gizi yang baik dan pembelajaran terkait persepsi citra tubuh agar memiliki persepsi body image yang positif. Diperlukan penelitian lebih lanjut untuk mengetahui faktor-faktor lain yang dapat mempengaruhi persepsi body image pada mahasiswa.
\end{abstract}

Kata Kunci : Body image; Kebiasaan jajan; Mahasiswa 


\section{PENDAHULUAN}

Periode remaja merupakan periode dimana kondisi fisik, psikis maupun perilaku akan berpengaruh terhadap pertumbuhannya. Menurut WHO usia remaja berkisar antara 12 hingga 24 tahun. Sedangkan Menkes RI tahun 2010 menerangkan bahwa usia remaja yaitu 10 hingga 19 tahun dan belum menikah. Masa remaja merupakan masa transisi antara pubertas dan masa dewasa, saat memasuki masa dewasa tentunya akan terdapat perubahan terutama dalam hal kebutuhan gizi seseorang. ${ }^{1}$ Dalam AKG 2019 pada kategori usia dewasa muda kebutuhan gizi untuk laki-laki sebesar 2650 kkal dan untuk perempuan sebesar $2250 \mathrm{kkal}^{2}$

Mahasiswa yang termasuk dalam kategori remaja akhir dan dewasa awal (18-26 tahun) mulai menunjukkan dirinya melalui perubahan dari gaya hidup dan pola konsumsi makan dan kebiasaan jajannya. ${ }^{3}$ Universitas Negeri Surabaya merupakan salah satu kampus yang berada di Surabaya, yaitu kota yang tergolong konsumtif dan memiliki mahasiswa yang dapat mengikuti perubahan gaya hidup. Kebanyakan mahasiswa yang berasal dari desa pun ikut mengalami perubahan gaya hidup saat mereka tinggal di kota, mulai dari interaksi dengan sesama teman baru, cara berbicara dan bersosialisasi serta kebiasaan pola konsumsi. Dikarenakan juga lokasi kampus Ketintang yang dekat dengan pusat perbelanjaan seperti mall dan banyak cafe-cafe tempat nongkrong anak muda, sehingga tak jarang dijumpai mahasiswa yang sering menghabiskan waktunya di mall setelah mereka selesai beraktifitas di kampus (Novitasani, 2014). ${ }^{4}$ Menurut Sugihartati dalam Jannah, Gaya hidup adalah salah satu upaya untuk menjadi lebih eksis dengan cara yang berbeda dengan kelompok tertentu. Mengenai dampak positif dan negatif dari gaya hidup saat ini, menyesuaikan dengan cara individu dalam menerapkannya di hidupnya. ${ }^{5}$ Di era modern ini, dampak negatif lebih dirasakan oleh mahasiswa. Khususnya mahasiswa di perkotaan metropolitan seperti Surabaya. Berdasarkan penelitian Jannah tahun 2019 menunjukkan bahwa gaya hidup memiliki pengaruh terhadap perilaku konsumtif mahasiswa, hal ini membuktikan bahwa gaya hidup yang semakin mewah akan mengakibatkan mahasiswa semakin konsumtif. Penelitian juga menunjukkan bahwa mayoritas mahasiswa tidak hanya melaksanakan perkuliahan tetapi juga melakukan berbagai kegiatan di luar kampus seperti mengunjungi mall dan berbelanja. Perilaku konsumtif tersebut tentunya akan menyebabkan mereka mengeluarkan sejumlah uang untuk kegiatan-kegiatan tersebut. Hasil penelitian Jannah juga menunjukkan bahwa literasi ekonomi tidak mempengaruhi perilaku konsumtif mahasiswa, studi ini membantah anggapan bahwa pengetahuan tentang ekonomi dapat mempengaruhi perilaku konsumtif. ${ }^{5}$

Salah satu fase perubahan dari mahasiswa ditandai dengan perubahan fisik, yaitu penampilan bentuk tubuh yang dianggap sebagai standar wajib yang diperhatikan oleh orang lain. ${ }^{6}$ Ketidakpuasan seseorang terhadap tubuh yang dimiliki dapat mempengaruhi 
terjadinya citra tubuh (body image). Menurut Honigmen dan Castle dalam penelitian Rombe tahun 2013, mereka mendefinisikan body image yaitu sebagai gambaran mental seseorang terhadap bentuk tubuh dan ukuran tubuh yang dimiliki, lalu tentang bagaimana seseorang mempersepsikan dan menilai apa yang dipikirkan terhadap tubuhnya, serta bagaimana dia menerima penilaian orang lain terhadap dirinya. ${ }^{7}$ Body image yang ideal akan mendorong seseorang untuk melakukan hal-hal yang dapat mencapai standar tersebut. ${ }^{6}$ Body image pada mahasiswa dapat terbentuk melalui interaksi antar mahasiswa, yaitu saling berkomunikasi dan memberikan pendapat tentang penampilan mereka sehingga dapat tercapai penampilan yang diharapkan. ${ }^{8}$ Kaitannya dengan persepsi body image seseorang, seseorang dengan tubuh kurus atau memiliki IMT yang rendah cenderung memiliki persepsi body image yang negatif dan mereka berpendapat bahwa dirinya belum memiliki tubuh yang proporsional. $^{9}$

Kehidupan mahasiswa adalah tahap transisi dari usia remaja ke kehidupan Universitas, mereka sering mengalami kekurangan waktu yang disebabkan oleh padatnya kegiatan akademik di perkuliahan yang dapat menimbulkan stres dan menyebabkan perubahan kebiasaan makan. ${ }^{10}$ Beberapa pola makan tidak sehat yang umum di kalangan mahasiswa yaitu melewatkan makan, sering makan diluar rumah, ngemil dan mengonsumsi makanan cepat saji dan kebiasaan jajan. Kebiasaan jajan merupakan masalah kesehatan masyarakat yang utama di kalangan remaja. Faktor lingkungan juga berkontribusi terhadap kebiasaan makan yang tidak sehat seperti banyaknya pusat perbelanjaan dan restoran cepat saji yang menjadi tempat untuk mempraktikkan kebiasaan makan yang tidak sehat. Meskipun perilaku mahasiswa ini dianggap sementara, kebiasaan tidak sehat yang telah dilakukan di usia ini umumnya akan tetap bertahan di kehidupan selanjutnya. ${ }^{11}$ Penelitian yang dilakukan oleh Bibiloni et al. tahun 2013 di kepulauan Balearic, Spanyol menunjukkan bahwa kelompok remaja perempuan tidak puas dengan citra tubuhnya dan sebanyak $96,6 \%$ dari mereka ingin menjadi lebih kurus, sementara pada kelompok remaja laki-laki yang gemuk mereka sebanyak $82,8 \%$ juga menginginkan bentuk tubuh menjadi lebih kurus, sedangkan 50,8\% remaja laki-laki yang gemuk puas dengan citra tubuhnya. Cara mereka untuk menjadi lebih kurus adalah dengan melakukan pembatasan konsumsi makanan yaitu lebih sering melewatkan sarapan serta kebanyakan dari mereka mengonsumsi makanan ringan dengan frekuensi yang lebih sedikit. ${ }^{12}$

Salah satu perubahan diri mahasiswa yaitu mengarah pada pandangan terhadap citra tubuhnya serta kebiasaan makan yang tidak sehat. Dalam studi Yong et al sebesar 52,8\% mahasiswa Cina melakukan pembatasan makan, dari hasil tersebut pola makan yang disertai dengan emosional dan pola makan yang tidak terkontrol lebih tinggi wanita daripada pria. Hasil penelitian juga menunjukkan bahwa mereka beranggapan dengan melakukan pembatasan makan akan mencapai bentuk tubuh yang diinginkan. ${ }^{13}$ Menurut penelitian 
Chairiah tahun 2012 seseorang yang memiliki citra tubuh negatif cenderung beranggapan bahwa makanan yang menjadi penyebab dirinya tidak menarik dan akhirnya dapat menimbulkan gangguan pola makan. ${ }^{14}$ Dalam penelitian Rijanti (2018) 42,2\% responden yang merasa tidak puas dengan bentuk tubuh yang dimiliki, meskipun mereka mempunyai tubuh yang tergolong ideal. Dikarenakan mereka lebih mementingkan bentuk tubuh dibanding dengan makanan, maka hal tersebut akan mengakibatkan pada pembatasan asupan makan yang salah. ${ }^{9}$ Dari hubungan tersebut, maka penelitian ini bertujuan untuk melihat persepsi mengenai citra tubuh (body image) dan kebiasaan jajan di kalangan mahasiswa Universitas Negeri Surabaya khususnya yang berada di kampus Ketintang. Penelitian Puspasari dan Farapti tahun 2020 menemukan sebanyak 64,3\% mahasiswa di Surabaya mengonsumsi jajan setiap hari ${ }^{3}$ dan penelitian Bimantara et al tahun 2019 menemukan 74\% siswa di Surabaya yang memiliki persepsi positif terhadap citra tubuhnya. ${ }^{15}$ Peneliti ingin mengetahui bagaimana kebiasaan jajan mahasiswa di Universitas Negeri Surabaya dan kaitannya terhadap persepsi citra tubuh yang dimiliki. Dengan demikian, dapat dihipotesiskan bahwa terdapat hubungan antara persepsi body image dengan kebiasaan jajan pada Mahasiswa Universitas Negeri Surabaya (khususnya di kampus Ketintang). Penelitian ini sudah disetujui oleh pihak Komisi Etika Penelitian dari Fakultas Kedokteran Gigi Universitas Airlangga Surabaya dengan Ethical Clearance no. 025/HRECC.FODM/l/2021.

\section{METODE PENELITIAN}

Penelitian ini menggunakan desain penelitian analitik observasional dengan pendekatan cross-sectional. Penelitian analitik dilakukan untuk mencari hubungan antar variable dan data akan dikumpulkan dalam satu waktu yang sama (correlational study), sedangkan pada pendekatan cross-sectional menurut Sri dalam penelitiannya pada tahun 2015 merupakan penelitian yang dilakukan hanya sampai pada tahap pengambilan data awal saja dan tidak melakukan tinjauan perkembangan oleh subjek, sehingga penelitian ini akan segera dilakukan analisis terhadap data yang sudah dikumpulkan. ${ }^{16}$

Pemilihan sampel menggunakan teknik Multistage Cluster Sampling, yaitu pemilihan sampel yang melalui dua tahapan atau lebih dalam proses pengambilan sampelnya. Pengambilan sampel dengan metode ini tidak langsung menarik sampel dari suatu elemen, tetapi penarikan melalui cluster terlebih dahulu. ${ }^{17}$ Sampel yang terpilih harus memenuhi kriteria inklusi yaitu Mahasiswa Unesa yang berada di kampus Ketintang, yaitu Fakultas IImu Sosial dan Hukum, Fakultas Ekonomi, Fakultas Teknik dan Fakultas Matematika dan IImu Pengetahuan Alam, berusia 18-26 tahun, bersedia menjadi responden dengan menandatangani inform consent. Didapatkan sampel pada penelitian sebanyak 100 responden yang sudah memenuhi kriteria inklusi. Data primer terdiri dari Karakteristik 
responden (Nama, Fakultas dan Jurusan, serta Usia). Persepsi body image diukur menggunakan Body Shape Questionnaire (BSQ) (Cooper et al., 1987). ${ }^{18}$ Pengukuran BSQ dilakukan dengan memberikan nilai terhadap 34 pertanyaan, setiap pertanyaan memiliki 6 kategori pilihan jawaban yaitu tidak pernah (1), jarang (2), kadang-kadang (3), sering (4), sangat sering (5) dan selalu (6). Total skor akhir yang akan didapatkan antara 34-204 dengan 4 kategori yaitu body image positif $<80$, body image negatif ringan $80-110$, body image negatif sedang 110-140 dan body image negatif berat $>140$.

Kebiasaan konsumsi jajan menggunakan instrumen semi kuantitatif Food Frequency Questionnaire (SQ-FFQ) yang meliputi daftar berbagai jenis makanan jajanan serta frekuensi konsumsi jajanan dalam 1 bulan terakhir. Penilaian kebiasaan jajan dengan memberikan skoring pada setiap kelompok frekuensi yang dikategorikan menjadi 5 kelompok, yaitu apabila konsumsi 2-3x sehari mendapat skor 50, 1x sehari mendapat skor 25, 3-5x seminggu mendapat skor 15, 1-2x seminggu mendapat skor 10 dan 1-3x sebulan mendapat skor 1 . Setelah data berdistribusi normal, dilakukan perhitungan nilai mean untuk menentukan cut of point dan dibuat coding yaitu sering dikonsumsi apabila lebih besar dari nilai mean $(>210,42) \pm S D$, dan tidak sering dikonsumsi apabila lebih kecil dari nilai mean $(<210,42) \pm S D .{ }^{19}$ Teknik pengumpulan data responden menggunakan Google Form dan aplikasi Whatsapp. Analisa data menggunakan uji korelasi Spearman dan data diolah menggunakan Microsoft Excel 2013 dan SPSS versi 16.0.

\section{HASIL PENELITIAN}

\section{A. Karakteristik Responden}

Untuk rata-rata usia responden yaitu 20,90 tahun dengan usia minimum 19 tahun dan maksimum berusia 23 tahun. Responden terbanyak adalah perempuan dengan usia 21 tahun (48,15\%). Distribusi frekuensi responden menurut usia dan jenis kelamin dapat dilihat pada tabel berikut.

Tabel 1 Distribusi Frekuensi Responden Menurut Usia dan Jenis Kelamin

\begin{tabular}{ccccccc}
\hline $\begin{array}{c}\text { Karakteristik } \\
\text { Usia (tahun) }\end{array}$ & \multicolumn{2}{c}{ Laki-laki } & \multicolumn{2}{c}{ Perempuan } & \multicolumn{2}{c}{ Total } \\
\cline { 2 - 7 } & $\mathrm{n}$ & $\%$ & $\mathrm{n}$ & $\%$ & $\mathrm{n}$ & $\%$ \\
\hline 19 & 1 & 5,26 & 5 & 6,17 & 6 & 6,0 \\
\hline 20 & 7 & 36,84 & 20 & 24,69 & 27 & 27,0 \\
\hline 21 & 5 & 26,32 & 39 & 48,15 & 44 & 44,0 \\
\hline 22 & 2 & 10,53 & 15 & 18,52 & 17 & 17,0 \\
\hline 23 & 4 & 21,05 & 2 & 2,47 & 6 & 6,0 \\
\hline Total & 19 & 100,0 & 81 & 100,0 & 100 & 100,0 \\
\hline
\end{tabular}




\section{B. Persepsi Body Image}

Persepsi Body Image diukur menggunakan metode pengukuran BSQ, yaitu dengan memberikan 34 pertanyaan kepada responden. Setiap item pertanyaan memiliki skala nilai 1 (tidak pernah), 2 (jarang), 3 (kadang-kadang), 4 (sering), 5 (sangat sering) dan 6 (selalu), pertanyaan ini dipilih sesuai dengan keadaan responden dalam 1 bulan terakhir. Total skor yang akan didapatkan setelah menjawab semua pertanyaan yaitu antara 34-204 dengan 4 kategori. Untuk distribusi frekuensi penilaian persepsi body image akan disajikan dalam tabel berikut.

Tabel 2 Distribusi persepsi body image responden

\begin{tabular}{ccc}
\hline Persepsi Body Image & $\begin{array}{c}\text { Jumlah } \\
(\mathrm{n})\end{array}$ & Persentase (\%) \\
\hline Positif $(<80)$ & 44 & 44,0 \\
\hline Negatif Ringan $(80-110)$ & 26 & 26,0 \\
\hline Negatif Sedang $(110-140)$ & 16 & 16,0 \\
\hline Negatif Berat $(>140)$ & 14 & 14,0 \\
\hline Total & 100 & 100,0 \\
\hline Nilai rata-rata \pm SD & & $93,39 \pm 35,9$ \\
\hline
\end{tabular}

Berdasarkan tabel diatas, responden yang memiliki body image positif sebesar $44 \%$ dan responden yang memiliki body image negatif sebesar $56 \%$ dengan body image negatif ringan terbanyak sebesar $26 \%$. Hasil rata-rata \pm SD dari data yang diperoleh yaitu $93,39 \pm$ 35,9 .

\section{Kebiasaan Jajan}

Kebiasaan jajan diperoleh dari pengisian instrumen semi kuantitatif Food Frequency Questionnaire (SQ-FFQ) melalui wawancara kepada responden. Distribusi kebiasaan jajan responden akan disajikan dalam tabel berikut.

Tabel 3 Distribusi Kebiasaan Jajan Responden

\begin{tabular}{ccc}
\hline Kebiasaan Jajan & Jumlah $(\mathrm{n})$ & Persentase $(\%)$ \\
\hline Sering $(>210,42)$ & 70 & 70 \\
\hline Tidak Sering $(<210,42)$ & 30 & 30 \\
\hline Total & 100 & 100 \\
\hline
\end{tabular}

Berdasarkan tabel diatas, didapatkan data bahwa sebagian besar responden mengaku sering jajan (70\%), dan sebagian besar dari mereka adalah perempuan (85,7\%). Distribusi skor kebiasaan jajan menurut jenis kelamin bisa dilihat pada tabel berikut: 
Tabel 4 Distribusi Kebiasaan Jajan menurut Jenis Kelamin Responden

\begin{tabular}{ccccccc}
\hline \multirow{2}{*}{ Skor Kebiasaan Jajan } & \multicolumn{2}{c}{ Perempuan } & \multicolumn{2}{c}{ Laki-Laki } & \multicolumn{2}{c}{ Total } \\
\cline { 2 - 8 } & $\mathrm{n}$ & $\%$ & $\mathrm{n}$ & $\%$ & $\mathrm{n}$ & $\%$ \\
\hline Sering & 60 & 74,07 & 10 & 52,63 & 70 & 70 \\
\hline Tidak Sering & 21 & 25,93 & 9 & 47,37 & 30 & 30 \\
\hline Total & 81 & 100 & 19 & 100 & 100 & 100 \\
\hline
\end{tabular}

D. Hubungan Persepsi Body Image dengan Kebiasaan Jajan

Tabel 5 Hubungan Persepsi body image dengan Kebiasaan jajan

\begin{tabular}{ccccccccccc}
\hline \multirow{2}{*}{$\begin{array}{c}\text { Frekuensi } \\
\text { Kebiasaan Jajan }\end{array}$} & $\begin{array}{c}\text { Body Image } \\
\text { Positif }\end{array}$ & $\begin{array}{c}\text { Body Image } \\
\text { Negatif } \\
\text { Rendah }\end{array}$ & $\begin{array}{c}\text { Body Image } \\
\text { Negatif } \\
\text { Sedang }\end{array}$ & $\begin{array}{c}\text { Body Image } \\
\text { Negatif } \\
\text { Berat }\end{array}$ & Total \\
\cline { 2 - 13 } & $\mathrm{n}$ & $\%$ & $\mathrm{n}$ & $\%$ & $\mathrm{n}$ & $\%$ & $\mathrm{n}$ & $\%$ & $\mathrm{n}$ & $\%$ \\
\hline Sering & 29 & 65,9 & 16 & 61,5 & 12 & 75 & 13 & 92,8 & 70 & 70 \\
Tidak Sering & 15 & 34,1 & 10 & 38,5 & 4 & 25 & 1 & 7,2 & 30 & 30 \\
Total & 44 & 100 & 26 & 100 & 16 & 100 & 14 & 100 & 100 & 100 \\
\hline \multicolumn{10}{c}{ Spearman's rho Sig. (2-tailed) } \\
\hline
\end{tabular}

Berdasarkan tabel diatas, persentase responden yang memiliki body image positif dengan kebiasaan jajan sering sebanyak $65,9 \%$. Sedangkan responden dengan body image negatif ringan sebanyak $61,5 \%$ memiliki frekuensi kebiasaan jajan sering. Untuk responden dengan body image negatif sedang sebanyak 75\% memiliki frekuensi kebiasaan jajan sering. Selanjutnya untuk responden dengan body image negatif berat sebanyak 92,8\% memiliki frekuensi kebiasaan jajan sering. Hasil analisis menunjukkan bahwa tidak ada hubungan antara persepsi body image dengan kebiasaan jajan pada responden $(p>0,05)$.

\section{PEMBAHASAN}

\section{Persepsi Body Image}

Hasil pengambilan data yang sudah dilakukan terhadap 100 responden terdapat $56 \%$ responden yang memiliki body image negatif, diantaranya $26 \%$ negatif ringan, $16 \%$ negatif sedang serta $14 \%$ negatif berat. Dengan ketidakpuasan citra tubuh yang dimiliki saat ini responden merasa bahwa tubuhnya terlalu besar dan takut menjadi gemuk, sehingga kebanyakan dari mereka melakukan diet karena mencemaskan bentuk tubuh yang dimiliki. Dari hasil tersebut, mayoritas responden perempuan yang memiliki body image negatif. Hasil tersebut hampir sama dengan penelitian yang dilakukan oleh Mahfudhotun S. pada tahun 2012 , bahwa sebanyak 50,8\% responden yang memiliki body image negatif, mereka sebagian besar tergolong memiliki status gizi yang normal dan juga masih terdapat responden yang tidak puas terhadap tubuhnya dan merasa tubuhnya lebih besar dari tubuh aktual mereka. ${ }^{20}$ Seperti penelitian yang dilakukan oleh Adriyanto dan Yushinta pada tahun 
2018 bahwa terdapat $44,4 \%$ remaja yang tergolong dalam status gizi normal memiliki body image negatif. Walaupun seseorang memiliki status gizi normal, tidak menutup kemungkinan bahwa dirinya juga merasa memiliki bentuk tubuh yang lebih besar dari tubuh aktualnya. ${ }^{21}$ Ketidakpuasan citra tubuh ditemukan juga dalam penelitian Gitika et al. pada tahun 2016 yang dilakukan pada remaja di Mauritus, hasilnya terdapat $74,5 \%$ responden yang memiliki ketidakpuasan dengan citra tubuhya serta tidak ada perbedaan dalam hal jenis kelamin, yaitu laki-laki $(76 \%)$ dan perempuan $(73,1 \%)$. Mereka baik laki-laki maupun perempuan sama-sama menderita ketidakpuasan citra tubuh (body image). ${ }^{22}$

Menurut hasil penelitian dari Wiwid pada tahun 2015, terdapat 50\% responden yang masuk dalam kategori body image negatif dan sebagian besar dari mereka adalah perempuan. $^{8}$ Penelitian Zol et al tahun 2018, menunjukkan bahwa persepsi citra tubuh antara mahasiswa Korea dengan mahasiswa Mongolia terdapat hasil yang berbeda yaitu sebanyak 64\% mahasiswa Korea menganggap diri mereka lebih gemuk dari citra tubuh idealnya saat ini, sedangkan hanya 34,6\% mahasiswa Mongolia yang ingin lebih kurus dari citra tubuhnya saat ini. Zol et al juga menerangkan bahwa orang korea memang lebih menyukai citra tubuh yang kurus dibandingkan negara lain seperti Cina dan Jepang, pengaruh media massa juga menjadi faktor penting dalam membentuk sikap terhadap penampilan dan kepercayaan diri dari mahasiswa Korea. ${ }^{23}$ Untuk itu, apabila tingkat kepuasan body image yang dimiliki seseorang tinggi dapat diartikan bahwa orang tersebut mengalami body satisfaction (body image positif), sebaliknya apabila tingkat kepuasan body image seseorang rendah maka orang tersebut mengalami body dissatifaction (body image negatif). ${ }^{24}$ Seseorang dengan persepsi body image positif akan mampu berfikir dengan kepercayaan tinggi dan memiliki harga diri yang tinggi juga, body image positif seseorang dapat dilihat dari kepedulian terhadap dirinya (selfcare) serta memiliki perhatian mengenai persoalan kesehatan, yaitu terkait dengan pemilihan konsumsi makanan sehat. Sebaliknya, seseorang dengan body image negatif akan merasa atau memiliki ketidakpuasan terhadap tubuhnya, memiliki pemikiran yang hanya terfokus pada bentuk serta berat badannya, merasa dirinya kurang sehat dan selalu memikirkan cara agar tubuhnya menjadi ideal, hal tersebut yang akhirnya bisa menyebabkan seseorang itu tidak lagi memperhatikan pemilihan makanan sehat untuk dirinya. ${ }^{25}$

\section{Kebiasaan Jajan}

Data kebiasaan jajan dari penelitian ini diperoleh dengan wawancara untuk pengisian instrumen semi kuantitatif Food Frequency Questionnaire (SQ-FFQ) yang terdiri dari daftar berbagai jenis makanan jajanan dalam frekuensi 1 bulan terakhir. Hasil penelitian menunjukkan bahwa kebiasaan jajan responden sebanyak $70 \%$ tergolong sering $(>210,42)$. Mayoritas jenis jajanan yang hampir setiap hari dikonsumsi oleh mereka adalah gorengan dan pentol. Dua jenis jajanan tersebut merupakan makanan yang umum di kalangan 
mahasiswa karena banyak dijumpai di sekitar kampus. Seringnya konsumsi jajan dan makanan ringan menjadi aspek yang dapat dikenali dari perilaku makan dewasa muda, penelitian yang dilakukan oleh Ganasegeran et al. di tahun 2012 pada mahasiswa Universitas Malaysia hanya $42,4 \%$ responden yang memiliki kebiasaan jajan dengan frekuensi $3 x$ atau lebih per minggu, dan sekitar $57,6 \%$ responden pernah jajan dengan frekuensi kurang dari 3x per minggu. ${ }^{11}$ Penelitian yang dilakukan pada remaja Suriah tahun 2014 oleh Bashour, ditemukan bahwa terdapat 53\% responden yang memiliki kebiasaan jajan sering. ${ }^{26}$ Walid et al pada tahun 2015 melakukan penelitian di Universitas Turku yang berada di barat daya Finlandia, hasilnya dari 1189 mahasiswa yang mengikuti penelitian sebanyak $50 \%$ saja yang memiliki kepatuhan dalam mengonsumsi jajanan yang tergolong ke dalam makanan sehat. Artinya kebiasaan konsumsi jajan dari sebagian mahasiswa Universitas Turku Finlandia tergolong sering yaitu dikonsumsi dalam beberapa kali selama seminggu. ${ }^{10}$ Menurut penelitian Anjani pada tahun 2014 terdapat beberapa faktor yang memengaruhi konsumsi jajanan pada siswa, yaitu faktor internal (pengetahuan, sarapan, bekal) dan faktor eksternal (orangtua, teman, media sosial serta karakteristik jajanan). Faktor dari pengetahuan, sarapan, keluarga, teman sebaya dan media massa tergolong dalam kategori tinggi yang bisa memengaruhi kebiasaan konsumsi jajanan pada siswa. ${ }^{27}$

Dalam studi Gitika et al. tahun 2016, konsumsi jajan ataupun makanan siap saji di kalangan remaja menurun. Dalam penelitiannya tidak ditemukan hubungan antara BMI dan frekuensi konsumsi jajan ataupun makanan siap saji, kemungkinan remaja yang sedang melakukan diet ataupun remaja dengan kelebihan berat badan atau obesitas lebih cenderung mengonsumsi jajan ataupun makanan siap saji sebagai cara untuk mengimbangi asupan energi mereka, dan hasilnya bahwa prevalensi jajan kurang lebih sama pada remaja yang puas dan yang tidak puas dengan tubuhnya. ${ }^{22}$ Hasil penelitian menunjukkan bahwa responden perempuan tergolong sering jajan $74,1 \%$ sedangkan laki-laki $52,6 \%$. Tetapi hal tersebut berbeda dengan penelitian yang dilakukan oleh Fitria di tahun 2013, hasilnya sebagian mahasiswi (45\%) mengonsumsi camilan dengan frekuensi 1-2 kali dalam seminggu (tidak sering). Sama halnya dengan penelitian yang dilakukan oleh Michel pada tahun 2014, hasil penelitian menunjukkan bahwa perempuan sebesar 53\% lebih sering mengonsumsi makanan jajanan dengan frekuensi kurang dari 3 kali sehari (tidak sering) sedangkan laki-laki yang lebih sering mengonsumsi makanan jajanan dengan frekuensi lebih dari 3 kali sehari. ${ }^{28}$ Menurut penelitian yang dilakukan oleh Aulia pada tahun 2012, hasilnya $52,1 \%$ remaja sering mengonsumsi jajan dan terdapat hubungan antara jenis kelamin dengan frekuensi konsumsi jajan pada remaja. ${ }^{29}$

\section{Hubungan Persepsi Body Image dengan Kebiasaan Jajan}

Dari hasil analisis korelasi Spearman tidak terdapat hubungan antara body image dengan kebiasaan jajan responden $(p>0,05)$. Didapatkan bahwa sebagian besar responden 
dengan body image yang negatif mengaku sering jajan (58,6\%). Meskipun beberapa dari responden mengaku bahwa mereka kurang puas dengan tubuh yang dimiliki, tetapi hal tersebut tidak berpengaruh dalam hal konsumsi jajan. Responden yang kurang puas terhadap citra tubuhnya tetap saja memiliki frekuensi konsumsi jajan sering bahkan ada juga yang setiap hari. Hal tersebut tidak sejalan dengan yang dijelaskan oleh Khomsan dalam penelitian Michel di tahun 2014 , bahwa persepsi dari seseorang mengenai tubuhnya memiliki hubungan dengan perilaku makan, seseorang yang memiliki kekuatan dengan keadaan tubuh yang dimiliki sering kali melakukan diet dengan menghindari mengonsumsi banyak makanan yang bisa membuat tubuhnya berubah, seperti kebiasaan sarapan dan mengonsumsi jajanan. ${ }^{28}$

Responden dalam penelitian yang memiliki body image positif juga sebagian besar memiliki kebiasaan jajan sering, hal ini dikarenakan mereka sudah puas dengan bentuk tubuh yang dimiliki sehingga tidak lagi memikirkan konsumsi makannya. Sedangkan responden yang memiliki body image negatif mungkin saja beranggapan bahwa untuk mencapai bentuk tubuh yang diharapkan orang akan memilih untuk mengonsumsi jajan dibandingkan dengan makanan utama, jadi mereka tidak mengurangi konsumsi jajan bahkan menambah konsumsinya. Seperti yang dijelaskan oleh Bibiloni et al. di tahun 2013 bahwa remaja yang memiliki ketidakpuasan terhadap bentuk tubuhnya, mereka cenderung mengurangi konsumsi makan hariannya dan tidak mengikuti atau merubah pola makan kearah yang lebih sehat seperti memperbanyak konsumsi buah dan sayur. ${ }^{12}$

Menurut penelitian yang dilakukan oleh Khairil pada tahun 2011, menunjukkan bahwa siswa perempuan cenderung mengalami kegemukan dibandingkan dengan siswa laki-laki, hal ini bisa terjadi dikarenakan perempuan cenderung menginginkan tubuh yang lebih kurus sehingga akan lebih banyak kecemasan dalam dirinya dan lebih memilih untuk diet. Anehnya dalam penelitian tersebut peningkatan frekuensi jajanan sehat semakin meningkatkan kemungkinan kelebihan berat badan, hal ini bisa disebabkan secara tidak sengaja siswa mengonsumsi energi yang berlebihan dari camilannya. ${ }^{30}$ Menurut hasil penelitian Hadia et al. pada tahun 2019 yang dilakukan pada mahasiswa di Universitas Sharjah Arab Saudi, terdapat lebih dari separuh perempuan $(59,3 \%)$ yang memiliki keinginan lebih kurus karena tidak puas dengan citra tubuhnya, 61,4\% dari mereka melakukan pembatasan diet. Sedangkan pada laki-laki sebagian besar (88,9\%) juga menginginkan lebih kurus, tetapi mereka lebih memilih untuk melakukan aktifitas fisik seperti olahraga daripada melakukan pembatasan diet. Ternyata terdapat juga mahasiswa laki-laki yang menginginkan tubuhnya lebih gemuk dengan tidak melakukan pembatasan diet yaitu sebanyak 54,7\% mahasiswa. Hadia et al. menerankan bahwa tidak ada perbedaan yang signifikan yang ditemukan antara kepuasan citra tubuh dengan aktifitas fisik serta perilaku makan atau diet diantara mahasiswa. ${ }^{31}$ 


\section{SIMPULAN DAN SARAN}

Persepsi body image responden sebagian besar negatif (56\%) dan sebagian besar responden mengaku memiliki kebiasaan jajan yang sering (70\%). Hasil uji korelasi Spearman menunjukkan bahwa tidak terdapat hubungan antara persepsi body image dengan kebiasaan jajan responden ( $p>0,05)$. Dapat disimpulkan bahwa sebagian besar dari responden kurang puas dengan citra tubuhnya, meskipun begitu tetap saja mayoritas dari mereka sering mengonsumsi jajan setiap harinya.

Disarankan untuk mahasiswa yang masih memiliki citra tubuh negatif perlu mendapatkan arahan seperti edukasi gizi yang baik dan pembelajaran terkait persepsi citra tubuh agar memiliki persepsi body image yang positif. Diperlukan penelitian lebih lanjut terkait dengan faktor-faktor yang memengaruhi persepsi body image pada mahasiswa.

\section{DAFTAR PUSTAKA}

1. Pritasari, Damayanti D, Tri Lestari N. GIZI DALAM DAUR KEHIDUPAN. Kementerian Kesehatan Republik Indonesia. 2017. 292 p.

2. Kementrian Kesehatan Republik Indonesia. Angka Kecukupan Gizi2019. Menteri Kesehat Republik Indones Peratur Menteri Kesehat Republik Indones. 2019;Nomor 65(879):2004-6.

3. Puspasari dan Farapti. Hubungan Konsumsi Makanan Jajanan Terhadap Status Gizi. J Chem Inf Model. 2020;110(9):1689-99.

4. Novitasani L, Handoyo P. PERUBAHAN GAYA HIDUP KONSUMTIF PADA MAHASISWA URBAN DI UNESA. Paradigma. 2014;02(03).

5. Jannah R. Pengaruh Literasi Ekonomi dan Gaya Hidup terhadap Perilaku Konsumtif Mahasiswa Jurusan Pendidikan Ekonomi UNESA. 2019;3(2):117-24.

6. Chairiah P. Hubungan Gambaran Body Image dan Pola Makan Remaja Putri di SMAN 38 Jakarta. Skripsi. 2012;

7. Rombe S. HUBUNGAN BODY IMAGE DAN KEPERCAYAAN DIRI DENGAN PERILAKU KONSUMTIF PADA REMAJA PUTRI DI SMA NEGERI 5 SAMARINDA. Psikoborneo. 2013;1(4):228-36.

8. Sudarmawan W. BODY IMAGE ANGGOTA ORGANISASI MAHASISWA. Skripsi. 2015;

9. Abdurrachim R, Meladista E, Yanti R. Hubungan Body Image Dan Sikap Terhadap Makanan Dengan Pola Makan Mahasiswi Jurusan Gizi Politeknik. Gizi Indones. 2018;41(2):117.

10. El Ansari W, Suominen S, Samara A. Eating habits and dietary intake: Is adherence to dietary guidelines associated with importance of healthy eating among undergraduate university students in Finland? Cent Eur J Public Health [Internet]. 2015;23(4):306-13. Available from: https://doi.org/10.21101/cejph.a4195 
11. Ganasegeran K, Al-Dubai SAR, Qureshi AM, Al-Abed AAAA, Am R, Aljunid SM. Social and psychological factors affecting eating habits among university students in a Malaysian medical school: A cross-sectional study. Nutr J. 2012;11(1):1-7.

12. Bibiloni MDM, Pich J, Pons A, Tur JA. Body image and eating patterns among adolescents. BMC Public Health. 2013;13(1).

13. Yong C, Liu H, Yang Q. The Relationship between Restrained Eating, Body Image, and Dietary Intake among University Students in China: A Cross-Sectional Study. 2021;

14. Chairiah P. Hubungan Gambaran Body Image dan Pola Makan Remaja Putri di SMAN 38 Jakarta. Skripsi. 2012;

15. Bimantara MD, Adriani M, Suminar DR. Hubungan Citra Tubuh dengan Status Gizi pada Siswi di SMA Negeri 9 Surabaya The Relationship between Body Image and Nutritional Status of Female Students in Senior High School 9 Surabaya. 2019;85-8.

16. Apiyati S. PERKEMBANGAN PEMAHAMAN SISWA SEKOLAH DASAR TENTANG MIKROORGANISME Universitas Pendidikan Indonesia | repository.upi.edu perpustakaan.upi.edu. 2015;37-51.

17. Cochran W. Sampling Techniques 3rd Edition, New York: John Wiley and Sons. Vol. 3, Sampling Techniques 3rd Edition. 2011. 1-500 p.

18. Cooper P., Taylor M., Cooper Z, Fairbum. The development and validation of the body shape questionnaire. int $\mathrm{J}$ Eat Disord [Internet]. 2013;6(4):485-94. Available from: https://doi.org/10.1002/1098-108X(198707)6:4\%3C485::AID-

EAT2260060405\%3E3.0.CO;2-O

19. Yuliastuti R. Analisis Karakteristik Siswa, Karakteristik Orang Tua dan Perilaku Konsumsi Jajanan pada Siswa-Siswi SDN Rambutan 04 Pagi Jakarta Timur Tahun 2011. 2012;

20. Machfudhotun S. Hubungan Body Image, Kebiasaan Makan, dan Aktivitas Fisik dengan Status Gizi Remaja Putri di SMA Plus Al-Fatimah Bojonegoro. Skripsi. 2019;

21. Yusintha AN, Adriyanto A. Hubungan Antara Perilaku Makan dan Citra Tubuh dengan Status Gizi Remaja Putri Usia 15-18 Tahun. Amerta Nutr. 2018;2(2):147.

22. Balluck G, Toorabally BZ, Hosenally M. Association between body image dissatisfaction and body mass index, eating habits and weight control practices among mauritian adolescents. Malays J Nutr. 2016;22(3):389-401.

23. Erdenebileg Z, Park SH, Chang KJ. Comparison of body image perception, nutrition knowledge, dietary attitudes, and dietary habits between Korean and Mongolian college students. 2018;12(2):149-59.

24. Marshall C, Lengyel C. Body Dissatifaction: Among Middle-aged and Older Women. Can J Diet Pract Res. 2012;73(2):e241-7.

25. Meriyanti F. Pengaruh Pengetahuan Gizi, Persepsi Body Image, Kebiasaan Makan dan 
Aktivitas Fisik Terhadap Status Gizi Mahasiswi Gizi dan Non Gizi IPB. Skripsi. 2013;

26. Bashour H. Survey of dietary habits of in-school adolescents in Damascus, Syrian. 2014;(May).

27. Pertiwi AM. Faktor-faktor yang Mempengaruhi Konsumsi dan Frekuensi Makanan Jajanan Siswa Kelas X Tata Boga SMK N 1 Sewon. Skripsi [Internet]. 2016;13-7. Available from: https://eprints.uny.ac.id/44322/1/Anjani Mega Pertiwi 14511247009.pdf

28. Erison M. Hubungan Antara Body Image dan Kebiasaan Makan dengan Status Gizi di SMA Padang. Skripsi [Internet]. 2014; Available from: http://ojs.ekasakti.org/index.php/UJSR/article/view/3

29. Aulia I. Hubungan antara karakteristik siswa, pengetahuan, media massa, dan teman sebaya dengan konsumsi makanan jajanan pada siswa SMA Negeri 68 Jakarta tahun 2012. Skripsi. 2012;

30. Isa K, Masuri M. The association of breakfast consumption habit, snacking behavior and body mass index among university students. Am J Food Nutr. 2011;1(2):55-60.

31. Radwan H, Hasan HA, Ismat H, Hakim H, Khalid H, Al-fityani L. Body Mass Index Perception, Body Image Dissatisfaction and Their Relations with Weight-Related Behaviors among University Students. 2019; 